\title{
Orlistat in the prevention of diabetes in the obese patient
}

\author{
Marcio C Mancini \\ Alfredo Halpern \\ Obesity and Metabolic Syndrome \\ Group, Endocrinology and Metabolism \\ Department, Faculty of Medicine, \\ University of São Paulo, São Paulo, SP, \\ Brazil
}

\begin{abstract}
There has been an increase in the concern about preventing type 2 diabetes mellitus (T2DM), a disease with great and increasing prevalence. The prevalence of obesity, physical inactivity, Western processed diet, important risk factors for the development of T2DM, are also rising. Free fatty acids are increased in obesity and reduce insulin clearance and increase hepatic glucose production. Implementation of a healthy lifestyle has been show to slow the progression of impaired glucose tolerance to T2DM. Orlistat is an inhibitor of lipase activity, with proved efficacy in body weight reduction and long-term management of obesity and more favorable effects on carbohydrate metabolism and it was prospectively shown in XENDOS study that orlistat promoted long-term weight loss and prevented T2DM onset in obese individuals with normal and impaired glucose tolerance at baseline over four years. This benefit could be associated to the weight loss itself, to the limited absorption of lipids and reduction of plasma free fatty acids, to increased production of incretins or to modulation of secretion of cytokines by adipocytes, all effects secondary to orlistat treatment. A proposed strategy is to identify subjects at highest risk to receive a drug intervention, using lifestyle interventions alone at the community level.
\end{abstract}

Keywords: type 2 diabetes mellitus, prevention, diabesity, obesity, metabolic syndrome, orlistat

\section{Prevalence}

There has been an increase in the concern about preventing the most usual type of diabetes, type 2 diabetes mellitus (T2DM). The public health burden of T2DM has been powerfully increased throughout the world, because T2DM remains a progressive disease. T2DM affects about $5 \%$ of Western populations and an estimated 170 million individuals worldwide (Wild et al 2004). In the US, the prevalence of T2DM increased 33\% from 1990 to 1998 (Mokdad et al 2000), was accountable for an estimated US\$132 billion in direct and indirect costs in 2002 and T2DM is the fifth leading cause of death (ADA 2003). Moreover, the lifetime risk for developing T2DM was estimated to be $32.8 \%$ and $38.5 \%$, respectively, for a man and a woman born in 2000 in the US (Narayan et al 2003). Not only the relatively great prevalence at present, but also the alarming increase in T2DM incidence in the coming decades, possibly caused by changes in human environment, lifestyle, and genetic susceptibility, can give rise to a global health problem. The number of diabetic individuals - the majority of them with T2DM - is projected to double, reaching about 350 million by the year 2025 (IDF 2006) and 360 million by 2030 (Wild et al 2004). By the reason of the escalating rate of T2DM and metabolic syndrome, is expected a concomitant increase in cardiovascular morbidity and mortality, coronary artery disease, end-stage renal disease, blindness, and lower extremity amputations (Isomaa et al 2001; Prisant 2004).

\section{Obesity and type 2 diabetes}

The pathogenesis of T2DM within the perception of the metabolic syndrome has been considered by Reaven in his Banting lecture (1988). He postulated that insulin resistance 
and consequent hyperinsulinemia could be the mutual pathological antecedents of the cardiovascular atherosclerotic pathological conditions (Reaven 1988). It is well known that the risk of developing clinical T2DM is strongly enhanced in the state of impaired glucose regulation or pre-diabetic states (impaired fasting glycemia or impaired glucose tolerance) and also the risk of developing cardiovascular complications is increased in these early states of glucose intolerance (Uwin et al 2002). In the impaired glucose tolerance state, postprandial blood glucose levels are moderately elevated, while on the contrary, fasting blood glucose can generally be maintained within the normal or near-normal range.

All-cause mortality associated with the pre-diabetic states is almost 2 times higher compared with normal glucose tolerance, and mortality per 1000 person-years is $20.8 \%$ and $40.9 \%$, respectively, for impaired glucose tolerance and for T2DM (Saydah et al 2001). Despite the fact that impaired glucose tolerance is frequently unrecognized, $17 \%$ of overweight Americans may have this state (Benjamin et al 2003). According to an expert guideline, the American Diabetes Association advises physicians taking into account screening for T2DM subjects with risk factors such as family history, overweight, gestational diabetes and hypertension (ECDCDM 1997). Menopause (Wu et al 2001) and hyperlipidemia (ADA Clinical Practice Recommendations 2004) are factors that also increase the risk of T2DM.

Comparably, the prevalence of obesity is also rising, with more than $60 \%$ of Americans, more than $50 \%$ of Europeans and Australians, and more than $40 \%$ of Brazilians contemporarily classified as overweight (Monteiro et al 2000; WHO 2000; James et al 2004). Between 1992 and 2002, the prevalence of overweight and obesity increased in all gender and age groups in China. The combined prevalence of overweight and obesity increased from $14.6 \%$ to $21.8 \%$ (Wang et al 2007). The increase in prevalence in China over the last 20 years was $400 \%$ (APCSC 2007). Obesity is the most important single risk factor for T2DM. Epidemiologic studies suggest that obesity and inactivity are substantial predictors for the development of T2DM among women (Hu et al 1999, 2001).

The Nurses' Health Study established that a body mass index (BMI) in the upper normal range was correlated with an increased risk of T2DM. Women with a BMI of 35 $\mathrm{kg} / \mathrm{m}^{2}$ or more had almost a 40 -fold risk to develop T2DM compared with women with BMI lower than $23 \mathrm{~kg} / \mathrm{m}^{2}$. This study also documented that weight change has a powerful influence on the risk of T2DM. A weight gain between 11 and $19.9 \mathrm{~kg}$ after 18 years of age represented a more than 5-fold risk of developing T2DM (Colditz et al 1995). Comparable information was documented for men in the Health Professionals' Study. In this study, data from a cohort of 51,529 US adult male health professionals were analyzed and individuals with a body mass index (BMI) of $35 \mathrm{~kg} / \mathrm{m}^{2}$ or more had a 42-fold relative risk to become T2DM compared with men with BMI lower than $23 \mathrm{~kg} / \mathrm{m}^{2}$. Moreover, waist circumference in the highest quintile was directly correlated to T2DM risk (Chan et al 1994).

Indeed, obesity and particularly intraabdominal adiposity with visceral fat deposition, is one modifiable risk factor directly involved in the increased prevalence of T2DM (Tuomilehto et al 2001). Visceral adipocytes have a higher metabolic turnover rate than peripheral adipocytes and the free fatty acids (FFA) are released in high concentrations and drained straight to the liver via the portal vein. Free fatty acids reduce insulin clearance and increase hepatic glucose production. Diminishing body fat has been show to slow the progression of impaired glucose tolerance to T2DM (Hu et al 2001). The risk of T2DM development in individuals with the central pattern of fat distribution is higher than the risk in individuals with a gluteal-femoral or peripheral type of fat distribution (Kissebah and Krakower 1994). A study of Japanese Americans evidenced that CT-mensurated intraabdominal fat area persisted a significant predictor of T2DM incidence still after adjustment for BMI, total body fat area and other risk factors for T2DM (Boyko et al 2000).

Visceral fat is the source of a number of substances which might play a role in the development of a cronic inflammatory (Dandona et al 2004) and insulin-resistant state (CallesEscandon and Cipolla 2001), as well as inadequate survival of pancreatic beta cells (Eldor and Raz 2006). These are interrelated metabolic abnormalities that are the root in the etiology of T2DM. Among these are tumor necrosis factoralpha (TNF- $\alpha$ ), interleukin 6 (IL-6), resistin, visfatin, and adiponectin (Borst 2004). The levels of these adipocytokines can be modulated by weight loss, with associated changes in insulin sensibility (Corpeleijn et al 2005). Hypoadiponectinemia may contribute to several aspects of the metabolic phenotype of specific ethnic groups, particularly, an increased central obesity and visceral fat and a remarkable increased risk of T2DM (Retnakaran et al 2006). Therefore, therapeutic strategies reducing pro-inflammatory cytokines and/or raising anti-inflammatory adiponectin may have a favorable effect in selected individuals.

Moreover, there is now evidence that impaired adipogenesis, adipocyte hypertrophy and pro-inflammatory factors may have an important role in the pathogenesis of T2DM. In 
fact, during positive energy balance, energy is stored as body fat, which serves important purposes, such as the release of fatty acids during fasting states, thus allowing fat oxidation by skeletal muscle. The storage of fat (lipogenesis) is first accomplished through enlargement of fat cells (hypertrophy). Further storage requires the recruitment, proliferation and differentiation of adypocites (adipogenesis). If adipogenesis is impaired, progressive adipocyte hypertrophy would lead to metabolic diseases related to excessive fat accumulation, among them T2DM (Bays 2005; Bays et al 2006).

\section{Physical activity and type 2 diabetes}

In addition to adiposity, physical activity is also a modifiable risk factor for T2DM. Individuals who are dynamical and active have a low prevalence of T2DM. However, if they they make a rapid shift from traditional rural active lifestyle to a modern western urbanized sedentary lifestyle, incidence of T2DM boosts (Knowler et al 1990). This phenomenon could be seen in Pima Indians (Knowler et al 1990), in the South Asian population in the UK (Mather and Keen 1985), but also in Japanese immigrants in the Southwest of Brazil (Ferreira et al 2002). Physical activity straightly enhances insulin-dependent glucose removal by the skeletal muscle, reduces visceral fat mass, and consequently improves insulin resistance (Kriska et al 2001). In fact, a more recent analysis of the Nurses' Health Study, including 84,941 female nurses followed for 16 years, showed that women with a health lifestyle had a much lower risk of developing T2DM than the general population. Women who exercised at least 7 hours per week reduced the risk of T2DM by $39 \%$ compared with women who exercised less than half hour per week (Hu et al 2001). In 7735 British men who were 40 to 59 years of age, moderate physical activity substantially diminished the risk of T2DM relative to sedentary men, after adjustment for BMI and age (Perry et al 1995).

An interesting recent health examination compared the age- and gender-adjusted prevalence of T2DM, obesity and lifestyle in two populations of Pima Indians that share considerable genetic similarity, but do not share the same environment: one living in the traditional environment in the Sierra Madre Mountains of Mexico and the other living in a western environment in Arizona, USA. The prevalence of T2DM in the Mexican Pima Indians was 6.9\%, less than one-fifth that in the US Pima Indians (38\%) and similar to that of non-Pima Mexicans (2.6\%). The prevalence of obesity was comparable in the Mexican Pima Indians (7\% in men and 20\% in women) and non-Pima Mexicans (respectively $9 \%$ and $27 \%$ ), but much lower than in the US Pima Indians (respectively 64\% and 75\%). Levels of physical activity were much higher in both Mexican groups than in US Pima Indians (Schulz et al 2006).

\section{Dietary factors and type $\mathbf{2}$ diabetes}

Dietary factors certainly play a role as another modifiable risk factor for T2DM. In the Health Professionals study, a diet high in whole grains was associated with a lower risk of T2DM (Fung et al 2002). The consumption of a diet rich in vegetables, fruit, fish, poultry and whole grains leads to a diminished risk of developing T2DM, when compared to a high consumption of a typical western diet based in red and processed meat (Fung et al 2004), dairy and high-fat ingredients (Meyer et al 2000; Van Dam et al 2002). A large cross-sectional study documented that a $40 \mathrm{~g}$ enhancement in daily fat intake yielded an increased risk of impaired glucose tolerance and T2DM, but it is not clearly evident if this increased risk is conditioned to the obese state or to the fat ingestion (Marshall et al 1991). The identification of risk factors is basic for the favorable implementation of prevention programs (Table 1).

Lifestyle modification is likely to have important effects on the morbidity and mortality of diabetes and should be recommended to all high-risk people. Recent results from the Finnish Diabetes Prevention Study showed that lifestyle interventions to prevent T2DM in men and women with impaired glucose tolerance are cost-effective (Lindgren et al 2007), although the program used in the DPP study was too expensive for a national program to be implemented (Eddy et al 2005).

T2DM is, therefore, a heterogeneous and polygenic disorder. Although our understanding of the etiology and pathogenesis of this disease is not complete, it is known that $\mathrm{T} 2 \mathrm{DM}$ is the result of both insulin resistance and relative insulin deficiency (Edelstein et al 1997; Weyer et al 1999). Insulin resistance is a fundamental defect known to precede the onset of T2DM by many years. In some subjects, betacells counterbalance for insulin resistance by enhanced insulin secretion and T2DM does not develop. Nevertheless, in many pre-diabetic individuals, beta-cell compensation to insulin resistance is ineffectively performed, and a hyperglycemic condition is generated.

\section{Nonpharmacological modes of T2DM prevention}

A huge number of studies address several forms by which T2DM could be prevented. Lifestyle changes, food intake modifications - for instance, lowering the fat content 
Table I Modifiable and nonmodifiable risk factors for implementation of T2DM prevention programs

\begin{tabular}{ll}
\hline Modifiable factors & Non-modifiable factors \\
\hline Obesity (mainly abdominal adiposity) & Ethnicity \\
Physical inactivity & Age \\
Smoking & Gender \\
Low fiber content of the diet & Genetic factors \\
High saturated fat/high trans fat in & Prior glucose intolerance/ \\
the diet/high processed meat intake & gestational diabetes \\
Low magnesium intake & Low birth weight \\
Low coffee/alcohol intake & Hypertension \\
Psychosocial stress & High triglyceride/Low HDL \\
& cholesterol \\
\hline
\end{tabular}

(Lovejoy 1999; Van Dam et al 2002) or enhancing the fiber and magnesium content of the diet (Lopez-Ridaura et al 2004) - and/or physical activity promoting weight loss (Eriksson and Lindgarde 1991; Pan et al 1997; Swinburn et al 2001; Tuomilehto et al 2001; Knowler et al 2002; Kosaka et al 2005), smoking status (Tuomilehto 2005), moderate coffee (Van Dam and Hu 2005) and moderate alcohol consumption (Conigrave et al 2001), and finally bariatric gastric surgery (Sjöström et al 2004) may be of benefit in the prevention of T2DM in morbidly obese patients (Gruber et al 2006).

These data lend powerful credence to the significant weight of lifestyle changes in T2DM prevention, but regardless of the fact that these modifications look to be operative in the prevention, it is highly questionable if these interventions would be sustained for the long-term. By the other hand, it is very clear that health providers need to assist their overweight patients with weight control (Tsai and Wadden 2005).

\section{Pharmacological modes of T2DM prevention: antidiabetic, antihypertensive, hypolipidemic agents; hormone replacement therapy}

In addition to lifestyle modifications and education, many oral antidiabetic agents have been evaluated in the context of T2DM prevention, showing reduction of incident T2DM. Although these post hoc analysis arouse interest and provocative reaction, these agents are glucose-lowering drugs, so that the clinical benefits in undoubtedly preventing T2DM has yet to be proved. Among there antidiabetic agents are: metformin in the US DPP Study (Knowler et al 2002), and possibly in the mid-term 3-year analysis of the ongoing EDIT trial (Scheen 2003); troglitazone in the TRIPOD interventional study in Hispanic women with a history of gestational diabetes (Buchanan et al 2002); acarbose in the STOP-NIDDM trial (Chiasson et al 2003), and also likely in mid-analysis of the EDIT trial (Scheen 2003), and rosiglitazone in the recently published DREAM trial (DREAM Trial Investigators 2006).

Also the role of blood pressure lowering agents has been studied in the prevention of T2DM in hypertensive patients. The rate of T2DM development was lower among ramipril-treated subjects in the HOPE trial (HOPE Study Investigators 2000), among captopril-treated patients in CAPP study (Hansson et al 1999) and among lisinopriltreated individuals in ALLHAT trial (ALLHAT 2002), expressing the well-known insulin sensitizing effect of angiotensin-converting-enzyme inhibitors, but also showing unfavorable effects of the conventional therapy (diuretics or beta-blockers). Compared to atenolol, losartan reduced the new incident cases of T2DM in the LIFE study (Dahlof et al 2002), but a possible limitation is that atenolol seems to promote T2DM, and hence, it is not possible to evaluate how protective losartan was. In the VALUE trial, valsartan reduced the risk of T2DM, when compared to amlodipine (Julius et al 2004). Treatment with candesartan decreased T2DM incidence in the ALPINE study in newly detected hypertensives (Lindholm et al 2003) and also in the CHARM trial in patients with heart failure (Yusuf et al 2005). Compared to diuretics, the rate of T2DM occurrence was lower among nifedipine-treated patients in INSIGHT study (Mancia et al 2003) and with amlodipine-treated individuals in the ALLHAT trial (ALLHAT 2002), may be reflecting adverse effects of diuretics or beta-blockers rather than beneficial effects of calcium channel blockers. Similarly, amlodipine (adding perindopril as required) in the ASCOT trial induced less T2DM than the combination atenolol and bendroflumethiazide (Dahlof et al 2005), and in the INVEST study a verapamil plus trandolapril-based regimen reduced the risk of new T2DM compared with a treatment based on hydrochlorothiazide plus atenolol (Pepine et al 2003).

The role of hypolipidemic agents in T2DM prevention was assessed. In the WOSCOPS study with pravastatin, a reduction of incident T2DM was observed (Freeman et al 2001) and the same was observed in the BIP study with bezafibrate retard (Tenenbaum et al 2004).

The answer to the query whether hormone replacement therapy is a feasible way to T2DM prevention persists uncertain. Although the risk of T2DM increased with the duration of estrogen use in Strong Heart study with postmenopausal American Indian women (Zhang et al 2002), a reduction in incident T2DM was detected with a combination 
of conjugated estrogen and medroxyprogesterone acetate in the HERS study with women with coronary heart disease (Kanaya et al 2003).

\section{Pharmacological modes of T2DM prevention: antiobesity agents}

As formerly affirmed, a modest 10\% weight reduction (Eriksson and Lindgarde 1991; Pan et al 1997; Swinburn et al 2001; Tuomilehto et al 2001; Knowler et al 2002; Kosaka et al 2005) and larger weight reduction through gastric surgery (Sjöström et al 2004; Pontiroli et al 2005) predict a reduced risk of T2DM. So, effective obesity therapies could improve glycemic status and prevent new T2DM (Padwal and Laupacis 2004; Padwal et al 2005).

It is reasonable to conclude that weight reduction with effective antiobesity agents (Halpern and Mancini 2005) may contribute to delay or prevent the progression from impaired glucose tolerance to overt T2DM in at risk obese individuals, but this datum is not available with most drugs used to treat obesity. A large long-term prospective study is ongoing with over 9000 patients (the Sibutramine Cardiovascular and diabetes OUTcome study) to examine wether or not sibutramine reduces the risk for cardiovascular complications in subjects at high risk for heart disease and should better determine the place of sibutramine in the prevention of T2DM (although T2DM is not a predefined endpoint of the study) (James 2005). Another ongoing randomized double-blind placebocontrolled trial (CRESCENDO) of rimonabant for reducing the risk of major cardiovascular events in abdominally obese patients with clustering risk factors may determine if treatment with rimonabant can prevent T2DM (though it is not a predefined endpoint) (see http://www.clinicaltrials. gov/ct/show/NCT00263042?order=2).

Orlistat is a specific and strong oral inhibitor of gastrointestinal lipase activity, achieving a $47 \%$ to $91 \%$ gastric lipase inhibition and a $51 \%$ to $82 \%$ pancreatic lipase inhibition in healthy volunteers (Carriere et al 2001). These lipases are responsible for the hydrolysis of ingested triglycerides into fatty acids and monoglycerides, which are therefore absorbed by the enterocytes. Orlistat has insignificant or no activity against phospholipases, chymotrypsin, trypsin and amylase. By orlistat action, ingested fat absorption is reduced by approximately one third and the nonabsorbed unbroken triglycerides, as well as orlistat, are eliminated in the feces (Guerciolini 1997). Orlistat has no systemic action, due to its minimal limited absorption (Zhi et al 1995).

The efficacy of orlistat in body weight reduction and long-term management of obesity has been shown in two large multicentre randomized double-blind 2-year trials, with 1187 (Sjöström et al 1998) and 743 obese patients (Davidson et al 1999). At the end of this study, patients receiving orlistat had lower plasma insulin levels compared to the levels at the beginning of the trial while these levels were not significantly different in placebo-treated patients $(64.5$ vs $84.0 \mathrm{pmol} / \mathrm{L}$ and 86.4 vs $86.3 \mathrm{pmol} / \mathrm{L}$, respectively, $\mathrm{p}=0.04$ between treatment groups). In the same study, the orlistat group had a lower increase in fasting serum glucose levels than the placebo group ( $+0.06 \mathrm{mmol} / \mathrm{L}$ vs $+0.26 \mathrm{mmol} / \mathrm{L}$, respectively, $\mathrm{p}=0.001$ between treatment groups). Furthermore, at the end of the multicentre European study (Sjöström et al 1998), orlistat also generated greater improvements in serum insulin and glucose levels after 1 and 2 years, when compared to the placebo group.

One European study assessed the impact of orlistat on weight loss, glycemic control and serum lipid levels in 391 obese patients with T2DM on sulphonylurea medications for one year and concluded that it is an effective treatment (Hollander et al 1998). Comparable results were achieved by Kelley and colleagues (2002) in obese diabetic patients on insulin and by Miles and colleagues (2002) in obese diabetic patients on sulphonylurea or metformin. Miles and colleagues (2002) also reported that 1-year treatment with orlistat was associated with significant improvement in blood pressure in orlistat-treated subjects, as well as greater improvements in total cholesterol and LDL cholesterol compared with placebo in overweight and obese patients with T2DM treated with metformin, consistent with the reduction in LDL/HDL ratio documented in many studies (Sjöström et al 1998; Rossner et al 2000; Kelley et al 2002; Halpern et al 2003). In these studies, all participants were encouraged to adhere to a low fat, weight reduction diet. One Latin-American trial of orlistat evaluating improvement in glycemic profile in obese diabetic patients demonstrated that subjects treated with orlistat plus a mildly controlled energy diet counseling for six months lost significantly more weight than those treated with placebo plus diet, and that, in addition, orlistat treatment was associated with greater improvements in diabetic metabolic parameters, lipid profile and anthropometric risk factors (Halpern et al 2003). Another 6-month study in a cohort of severely young obese diabetic Chinese patients reduced the levels of glycosylated hemoglobin and fasting plasma glucose (Tong et al 2002). In general, these studies showed that more patients in the orlistat group than in placebo group either reduced or discontinued one or more antidiabetic drugs or reduced insulin dose and, in opposition, more placebo-treated patients, compared with orlistat-treated subjects required supplemental 
dosages of antidiabetic medications. The improvements in glycemic profile accomplished in orlistat-treated diabetic individuals in some studies (Halpern et al 2003; Didangelos et al 2004) can be comparable to those documented in trials with antidiabetic medications (Hoffmann and Spengler 1994, 1997; Johansen 1999).

These observations suggest that orlistat may be an efficient and a safe adjunct to dietary intervention and conventional antidiabetic pharmacotherapy in the global treatment of obese diabetic patients and several meta-analyses have concluded that orlistat is effective in the treatment of T2DM in obese patients (Keating and Jarvis 2001; Scheen and Ernest 2002).

An initial effort to state that anti-obesity drugs could prevent T2DM was a multicenter evaluation of orlistat, a pooled post hoc analysis $(n=675$ obese adults with impaired glucose tolerance treated for a men follow-up of 582 days) of three randomized, placebo-controlled clinical trials (Heymsfield et al 2000). Obese nondiabetic individuals received either orlistat (120 mg three times a day with food) or placebo for two years, combined with a mild low energy diet. In orlistat group, less subjects with impaired glucose tolerance at baseline developed T2DM (3\%) compared to subjects in placebo group (7.6\%). Moreover, considering individuals with impaired glucose tolerance, fasting glucose levels normalized in more orlistat-treated patients than in placebotreated subjects (respectively, $72 \%$ vs $49 \%, p=0.04$ ). These findings denote that orlistat treatment has a more favorable effect than placebo on carbohydrate metabolism and can prevent T2DM onset in obese individuals with impaired glucose tolerance at baseline. This report was a retrospective meta-analysis and confirmation of the results by prospective trials was needed.

This ratification came from the XENDOS study (Torgerson et al 2004), a prospective multicenter randomized doubleblind, placebo-controlled, parallel group study, performed in Sweden over a period of four years, aimed to investigate the effectiveness of orlistat plus lifestyle changes compared with lifestyle modifications alone in 3305 patients with BMI $\geq 30 \mathrm{~kg} / \mathrm{m}^{2}$, for T2DM prevention. This is one important difference between XENDOS study and other prevention studies: both groups in XENDOS were prescribed intensive lifestyle modifications, besides receiving either a placebo or an active treatment. Non-diabetic subjects were enrolled, $21 \%$ with impaired glucose tolerance, $79 \%$ with normal glucose tolerance and randomized to orlistat (120 mg three times a day with meals) or matched placebo. The average compliance with the study drug from first dose until treatment termination was $93 \%$ for orlistat patients and placebo patients. Overall, $4 \%$ of placebo patients and $8 \%$ of orlistat patients withdrew from the study because of adverse events or laboratory abnormalities (mainly due to gastrointestinal events). A diet was prescribed with an intense daily calorie deficit of $800 \mathrm{kcal}$ from the estimated total daily energy expenditure. In addition, all individuals were encouraged to participate in moderate daily physical exercise. A $75 \mathrm{~g}$ oral glucose tolerance test was performed at baseline and every six months (Torgerson et al 2004).

Weight loss was greater in orlistat group $(-6.9 \mathrm{~kg}, \mathrm{n}=1640$ completers; $-5.8 \mathrm{~kg}$ in LOCF analysis) than in placebo group $(-4.1 \mathrm{~kg}, \mathrm{n}=1647$ completers; $-3 \mathrm{~kg}$ in LOCF analysis, $\mathrm{p}=0.001)$. Regional body composition study with computerized tomography at the fourth lumbar vertebra showed significant visceral adipose tissue reduction in orlistat-treated patients, but not in placebo-treated patients (Brandberg et al 2003). It is remarkable that the placebo group was treated with lifestyle modifications and lost an expressive amount of weight throughout the study, comparable with that in intensive lifestyle intervention branches of other preventive studies (Tuohmilehto et al 2001; Knowler et al 2002). In spite of that, the difference in weight loss between groups was able to diminish T2DM incidence $(6.2 \%$ in orlistat-treated patients vs $9.0 \%$ in placebo-treated subjects, $\mathrm{p}=0.003, \mathrm{RR}$ reduction $=37.3 \%$ ). Moreover, the weight loss achieved by patients with impaired glucose tolerance with orlistat plus lifestyle intervention was comparable to that of normal glucose tolerance subjects (Torgerson et al 2004).

In obese individuals with impaired glucose tolerance, the conversion rate to T2DM was $28.8 \%$ in placebo-treated patients vs $18.8 \%$ in orlistat-treated patients $(\mathrm{p}=0.002, \mathrm{RR}$ reduction $=45 \%$ ) (Figure 1$)$. Since the accumulative incidence of T2DM in subjects with normal glucose tolerance at baseline was low, no difference was perceptible between orlistat-treated and placebo-treated individuals in this subgroup. In spite of this, there was a significant reduction in fasting insulin levels at the end of first and fourth year in the orlistat-treated population $(p<0.001$ between treatment groups) (Torgerson et al 2004). The accumulative occurrence of T2DM in placebo-treated patients with impaired glucose tolerance $(14.2 \%)$ was comparable to that of the intensive lifestyle intervention arms of other preventive studies $(11 \%$ and 14.4\%) (Tuohmilehto et al 2001; Knowler et al 2002), but the inclusion of orlistat to lifestyle changes reduced incident T2DM in individuals with impaired glucose tolerance by more than $50 \%$ when compared with placebo-treated patients (Torgerson et al 2004). The number of obese patients with 


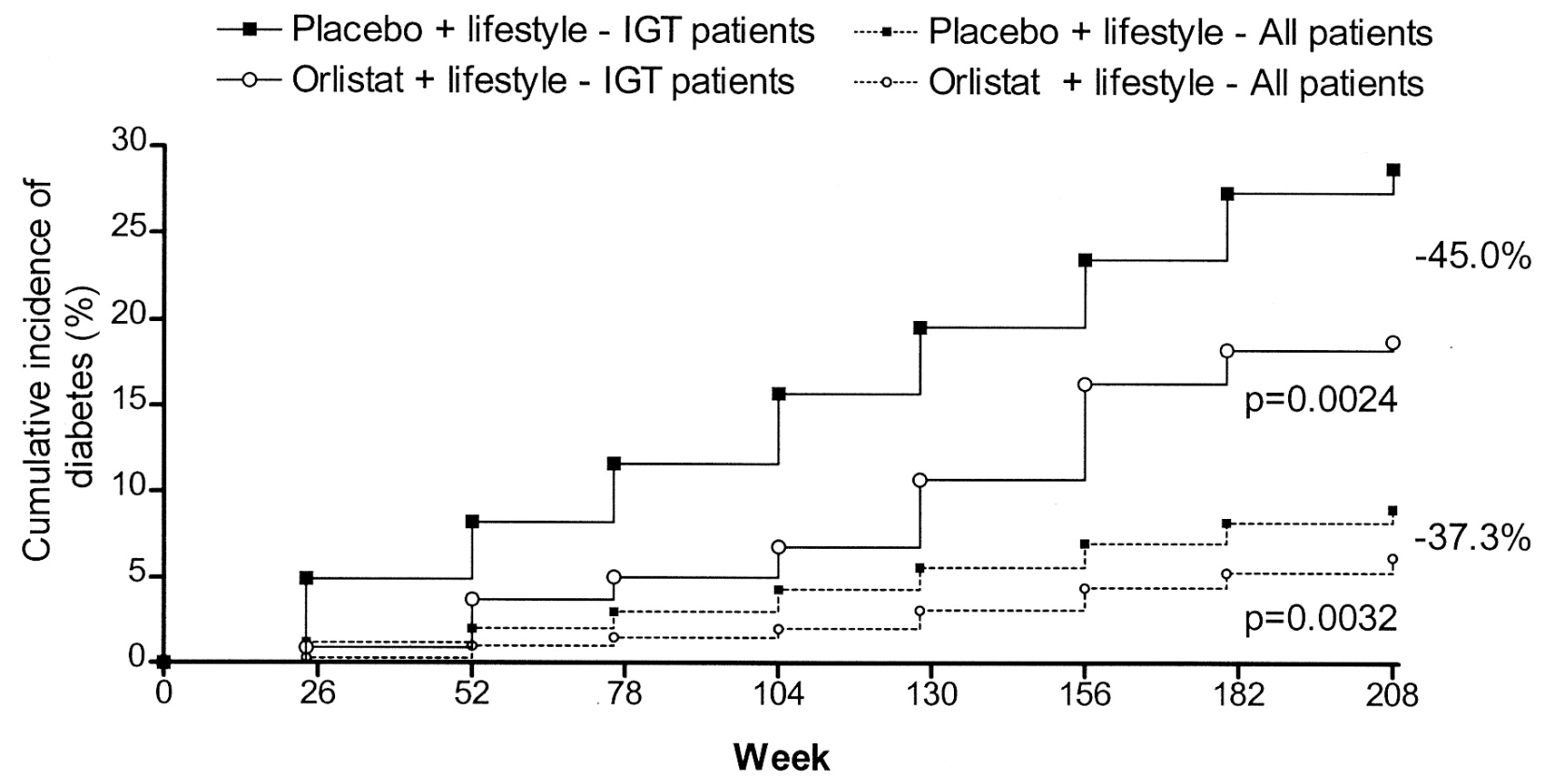

Figure I Incidence of T2DM by study group in XENDOS study. Cumulative incidence is shown in all obese patients and only in obese patients with impaired glucose tolerance at baseline. The decrease in the risk of developing diabetes with orlistat plus lifestyle intervention compared with placebo plus lifestyle intervention is indicated. $P$ values shown are for the log-rank test. Copyright @ 2004 . Reproduced with permission from Torgerson JS, Hauptman J, Boldrin MN, et al. 2004. XENical in the prevention of diabetes in obese subjects (XENDOS) study: a randomized study of orlistat as an adjunct to lifestyle changes for the prevention of type 2 diabetes in obese patients. Diabetes Care, 27:I55-6I. Erratum in: Diabetes Care, 2004 27:856.

impaired glucose tolerance needed to be treated (NNT) with orlistat plus lifestyle changes (rather than lifestyle changes alone) to avoid one case of T2DM was 10, but considering all participants, NNT was 36/4 years. XENDOS was the first study to illustrate that the anti-obesity agent orlistat plus lifestyle changes were able to improve weight loss and reduce incident T2DM in obese individuals above the result achieved with implementation of lifestyle modifications alone over four years. The preventive effect of orlistat in the studied subjects was mainly attributable to its favorable influence on individuals with impaired glucose tolerance.

Another recently published study evaluated efficacy of orlistate in the maintenance of weight loss over 3 years following a major weight loss induced by very-low-energy diet (VLED) in abdominally obese patients with metabolic risk factors such as dyslipidemia, impaired fasting glucose and diet-treated T2DM. The addition of orlistate to lifestyle intervention was associated with maintenance of an extra $2.4 \mathrm{~kg}$ weight loss after VLCD for up to 3 years and with a reduced occurrence of T2DM (Richelsen et al 2007).

Changes in inflammatory mediators TNF- $\alpha$ and IL- 6 were evaluated before and after one year of treatment with orlistat and placebo in obese subjects. Weight reduction was associated with diminished levels of TNF- $\alpha$ and IL- 6 in both groups, but at the end of the study, TNF- $\alpha$ and IL-6 levels were lower in orlistat-treated subjects (Samuelsson et al 2003). A significant reduction in leptin and high sensitive C-reactive protein, greater in orlistat-treated than in placebotreated patients was documented by Hsieh et al (2004) in a one-year study with 180 overweight individuals.

Another 6-month trial compared orlistat- and sibutraminetreated morbidly obese women, and documented that, although orlistat group achieved a mean weight loss of $2.5 \%$ (nearly half of the weight loss of the sibutramine group) and did not show significant change in metabolic parameters, surprisingly there was a greater and significative decrease of resistin associated with comparable increase in adiponectin (Valsamakis et al 2004). A significant increase in adiponectin in orlistat-treated patients was also observed by Hsieh and colleagues (2004).

It is known that a single dose of orlistat, given before a relatively high fat content meal in overweight patients with T2DM is associated with lower postprandial levels of plasma FFA compared with placebo (Tan et al 2002) and, since the publication of Randle's original hypothesis (Randle et al 1963), many satisfactory and convincing studies have confirmed that plasma levels of FFA can modulate the severity of insulin resistance in T2DM, inhibiting whole 
body glucose utilization and oxidation (Ferrannini et al 1983; Piatti et al 1996; Randle 1998; Santomauro et al 1999; Kelley et al 2001).

A huge body of data documents that the clinical benefit for the obese patient with T2DM usually depends on the extent of weight loss (Wing et al 1987, 1990; Williams et al 1998). A very interesting 6-month trial examined weight loss-dependent and independent effects of orlistat, using behavioral intervention combined with placebo- controlled treatment with orlistat. Even though weight loss was nearly similar in orlistat and placebo-treated patients (nearly $10 \%$ of baseline weight), and despite highly comparable changes in regional adiposity, including almost identical decrements of visceral adipose tissue, hepatic steatosis, and skeletal muscle fat content, improvement in insulin sensitivity measured by euglycemic hyperinsulinemic clamp was significantly greater with orlistat therapy (Kelley et al 2004). This study showed that the improvement in insulin sensitivity was not related only to the negative energy balance and loss of adipose tissue, factors that did not account for the differential effect, because the rates and amounts of weight loss in both arms of the intervention were highly comparable. A differential treatment effect on plasma FFA likely contributed to the differences in the insulin sensibility status: there was greater reduction in fasting hyperinsulinemia and also in fasting and insulinsuppressed plasma FFA in subjects receiving orlistat, probably related to effects on triglyceride absorption and postprandial lipemia, effect that persisted significant even after statistical adjustment for weight loss. Plasma FFA levels were a strong correlate of insulin sensitivity both before and after weight loss.

Another possibility is an incretin response to orlistat treatment. In fact, the reduced absorption of fat and the increase in intestinal fat content may lead to increased secretion of glucagon-like peptide 1 (GLP-1) and glucose-dependent insulinotropic peptide (GIP) (Thomsen et al 2003), gut hormones that are secreted in response to food intake, and stimulate insulin secretion (Vilsboll et al 2003). Orlistat increases postprandial GLP-1 levels, enhancing the insulin secretory response to the meal and blunting the postprandial rise in glucose in obese patients with T2DM. The increased GLP-1 levels, which lead to decreased food intake, may also contribute to the weight loss that is associated with the use of orlistat (Damci et al 2004).

Whether these findings provide a physiopathological basis for the benefits in carbohydrate metabolism associated to the weight loss itself, to the limited absorption of lipids and reduction of plasma FFA, to increased production of incretins or to modulation of secretion of cytokines by fat cells (Table 2), all achieved by treatment with orlistat and lifestyle changes remains to be elucidated.

Genetic components - as well as behavioral and environmental factors - modify the risk of occurrence of T2DM and some populations have a higher risk of developing T2DM. Consequently, experiments that involved a rather limited demographic sample may not be promptly generalized to the population as a whole. A proposed strategy is to identify subjects most likely to benefit, or at highest risk to receive an aggressive and maybe multiple drug intervention, universalizing a planned effort at lifestyle interventions at the community level (Satterfield et al 2003; Anderson Jr 2005; Norris et al 2006).

Specially with respect to oral hypoglycemic agents, but still in relation to orlistat, whether pharmacological preventive therapy merely postpone or mask the diagnosis of T2DM, instead of put forth an authentic preventive outcome is a critical and uncertain matter. Drugs that reduce plasma glucose levels may only reduce the concentrations to a limit situated below than that demanded for the precise diagnosis of T2DM. To show that T2DM is truly prevented, coming studies need to prove arrest of the pathological processes and since the interval between the beginning of beta-cell impaired function and development of T2DM according to the UK Prospective Diabetes Study (UKPDS) Group is about ten years (UKPDS Group 1995), surveillance periods will need to be considerably prolonged.

One can infer that probably long-term therapy with agents directed toward prevention of T2DM will be needed and that another important matter is the potential adverse events associated with pharmacological tactic for prevention of T2DM. Gastrointestinal adverse events were partly responsible for discontinuation rates in XENDOS study (Torgerson et al 2004).

Table 2 Evidence for the benefits in carbohydrate metabolism and T2DM prevention achieved with orlistat treatment

\begin{tabular}{ll}
\hline $\begin{array}{l}\text { Putative factor implicated in T2DM } \\
\text { prevention with orlistat }\end{array}$ & Reference \\
\hline Reduction in free fatty acid levels & $\begin{array}{l}\text { Tan et al 2002; Kelley } \\
\text { et al 2004 }\end{array}$ \\
$\begin{array}{l}\text { Reduction of proinflammatory } \\
\text { adipocytokine levels }\end{array}$ & Valsamakis et al 2004 \\
$\begin{array}{l}\text { Enhancement in anti-inflammatory } \\
\text { adipocytokine levels }\end{array}$ & Valsamakis et al 2004 \\
Enhancement in incretin levels & Damci et al 2004 \\
\hline
\end{tabular}


A factor that must be considered in forming a decision about pharmacological T2DM preventive intervention is the cost-effectiveness of the therapy. Although supplementing standard T2DM management with orlistat seems to be a reasonably effective and cost-effective treatment option for overweight patients with T2DM (Maetzel et al 2003) and for the treatment of obesity if only treatment responders continue treatment (Foxcroft et al 2005; Lacey et al 2005), the cost-effectiveness of T2DM preventative intervention with orlistat was not yet documented.

Efforts should be directed to identify individuals with pre-diabetic states, family history of T2DM or high risk ethnic background and, from a public health point of view, preventive measures should ideally be focused in pediatric patients at high risk. In the future, genetic variations, as well as interactions between genetic and environmental pathways (Andrulionyte et al 2004; Zacharova et al 2005a, 2005b; Park et al 2006a, 2006b; Retnakaran et al 2006) may turn out T2DM prevention easier, affording the possibility of an individualized preventive measure based on this knowledge (Park 2004). New therapeutic agents with unique mode of action, incretins, stimulate the secretion of insulin, suppress glucagon secretion and increase the mass of pancreatic betacells (Xu et al 1999; Meier et al 2003; Nauck and Meier 2005). These agents, exenatide and liraglutide could halt and possibly prevent progression to T2DM, but further studies are certainly needed.

To summarize, an important body of evidence from large clinical trials establishes that T2DM is a preventable disease (ADA Clinical Practice Recommendations 2004). XENDOS study presented for the first time that an antiobesity agent in combination with lifestyle interventions over four years is of greater benefit than lifestyle attitude modifications alone, specially in high risk individuals with impaired glucose tolerance resulting in more weight loss and greater amelioration in cardiovascular risk factors.

\section{References}

ALLHAT Officers and Coordinators for the ALLHAT Collaborative Research Group. The Antihypertensive and Lipid-Lowering Treatment to Prevent Heart Attack Trial. 2002. Major outcomes in high-risk hypertensive patients randomized to angiotensin-converting enzyme inhibitor or calcium channel blocker vs diuretic: The Antihypertensive and Lipid-Lowering Treatment to Prevent Heart Attack Trial (ALLHAT). JAMA, 288:2981-97. Erratum in: JAMA, 2003 289:178. JAMA, 2004 291:2196.

[ADA] American Diabetes Association. 2003. Economic costs of diabetes in the U.S. in 2002. Diabetes Care, 26:917-32.

American Diabetes Association Clinical Practice Recommendations. 2004. Prevention or delay of type 2 diabetes. Diabetes Care, 27(Suppl 1): S47-54.

Anderson Jr DC. 2005. Pharmaological prevention or delay of type 2 diabetes mellitus. Ann Pharmacother, 39:102-9.
Andrulionyte L, Zacharova J, Chiasson JL, et al. STOP-NIDDM Study Group. 2004. Common polymorphisms of the PPAR-gamma2 (Pro12Ala) and PGC-1alpha (Gly482Ser) genes are associated with the conversion from impaired glucose tolerance to type 2 diabetes in the STOP-NIDDM trial. Diabetologia, 47:2176-84.

[APCSC] Asia Pacific Cohort Studies Collaboration. 2007. The burden of overweight and obesity in the Asia-Pacific region. Obes Rev, 8:191-6.

Bays H. 2005. Adiposopathy, metabolic syndrome, quantum physics, general relativity, chaos and the Theory of Everything. Expert Rev Cardiovasc Ther, 3:393-404.

Bays H, Blond L, Rosenson R. 2006. Adiposopathy: how do diet, exercise and weight loss drug therapies improve metabolic disease in overweight patients? Expert Rev Cardiovasc Ther, 4:871-95.

Benjamin SM, Valdez R, Geiss LS, et al. 2003. Estimated number of adults with prediabetes in the U.S. in 2000. Diabetes Care, 26:645-9.

Borst SE. 2004. The role of TNF-alpha in insulin resistance. Endocrine, 23:177-82.

Boyko EJ, Fujimoto WY, Leonetti DL, et al. 2000. Visceral adiposity and risk of type 2 diabetes: a prospective study among Japanese Americans. Diabetes Care, 23:465-71.

Brandberg J, Lönn L, Peltonen M, et al. 2003. Body composition changes during 4 years of treatment with orlistat vs placebo (The XENDOS study). Int J Obes, 27(Suppl 1):S100.

Buchanan TA, Xiang AH, Peters RK, et al. 2002. Preservation of pancreatic beta-cell function and prevention of type 2 diabetes by pharmacological treatment of insulin resistance in high-risk Hispanic women. Diabetes, 51:2796-803.

Calles-Escandon J, Cipolla M. 2001. Diabetes and endothelial dysfunction: a clinical perspective. Endocr Rev, 22:36-52.

Carriere F, Renou C, Ransac S, et al. 2001. Inhibition of gastrointestinal lipolysis by orlistat during digestion of test meals in healthy volunteers. Am J Physiol Gastrointest Liver Physiol, 281:G16-28.

Chan JM, Rimm EB, Colditz GA, et al. 1994. Obesity, fat distribution, and weight gain as risk factors for clinical diabetes in men. Diabetes Care, 17:961-9.

Chiasson JL, Josse RG, Gomis R, et al. 2003. Acarbose treatment and the risk of cardiovascular disease and hypertension in patients with impaired glucose tolerance : the STOP NIDDM trial. JAMA, 290:486-94.

Colditz GA, Willet WC, Rotznitzky A, et al. 1995. Weight gain as a risk factor for clinical diabetes in women. Ann Intern Med, 122:481-6.

Conigrave KM, Hu BF, Camargo CA, et al. 2001. A prospective study of drinking pattern in relation to risk of type 2 diabetes among men. Diabetes, 50:2390-5.

Corpeleijn E, Saris WH, Jansen EH, et al. 2005. Postprandial interleukin-6 release from skeletal muscle in men with impaired glucose tolerance can be reduced by weight loss. J Clin Endocrinol Metab, 90:5819-24.

Dahlof B, Devereux RB, Kjeldsen SE, et al. 2002. Cardiovascular morbidity and mortality in the Losartan Intervention for Endpoint reduction in hypertension study (LIFE): a randomised trial against atenolol. Lancet, 359:1004-1010.

Dahlof B, Sever PS, Poulter NR, et al. 2005. Prevention of cardiovascular events with an antihypertensive regimen of amlodipine adding perindopril as required versus atenolol adding bendroflumethiazide as required, in the Anglo-Scandinavian Cardiac Outcomes Trial-Blood Pressure Lowering Arm (ASCOT-BPLA): a multicentre randomised controlled trial. Lancet, 366:895-906.

Damci T, Yalin S, Balci H, et al. 2004. Orlistat augments postprandial increases in glucagon-like peptide 1 in obese type 2 diabetic patients. Diabetes Care, 27:1077-80.

Dandona P, Aljada A, Bandyopadhyay A. 2004. Inflammation: the link between insulin resistance, obesity and diabetes. Trends Immunol, 25:4-7.

Davidson MH, Hauptman J, Di Girolamo M, et al. 1999. Weight control and risk factor reduction in obese subjects treated for 2 years with orlistat: a randomized controlled trial. JAMA, 281:235-42. 
Didangelos TP, Thanopoulou AK, Bousboulas SH, et al. 2004. The ORLIstat and CArdiovascular risk profile in patients with metabolic syndrome and type 2 DIAbetes (ORLICARDIA) Study. Curr Med Res Opin, 20:1393-401.

DREAM (Diabetes REduction Assessment with ramipril and rosiglitazone Medication) Trial Investigators; Gerstein HC, Yusuf S, Bosch J, et al. 2006. Effect of rosiglitazone on the frequency of diabetes in patients with impaired glucose tolerance or impaired fasting glucose: a randomised controlled trial. Lancet, 368:1096-105.

Eddy DM, Schlessinger L, Kahn R. 2005. Clinical outcomes and costeffectiveness of strategies for managing people at high risk for diabetes. Ann Intern Med, 143:251-64.

Edelstein SL, Knowler WC, Bain RP, et al. 1997. Predictors of progression from impaired glucose tolerance to NIDDM: an analysis of six prospective studies. Diabetes, 46:701-10.

Eldor R, Raz I. 2006. Lipotoxicity versus adipotoxicity-The deleterious effects of adipose tissue on beta cells in the pathogenesis of type 2 diabetes. Diabetes Res Clin Pract, 74(2 Suppl):S3-8.

Eriksson KF, Lindgarde F. 1991. Prevention of type 2 (non-insulin-dependent) diabetes mellitus by diet and physical exercise. The 6-year Malmo feasibility study. Diabetologia, 34:891-8.

[ECDCDM] The Expert Committee on the Diagnosis and Classification of Diabetes Mellitus. 1997. Report of the Expert Committee on the Diagnosis and Classification of Diabetes Mellitus. Diabetes, 20:1183-97.

Ferrannini E, Barrett EJ, Bevilacqua S, et al. 1983. Effect of fatty acids on glucose production and utilization in man. J Clin Invest, 72:1737-47.

Ferreira SR, Lerario DD, Gimeno SG, et al. 2002. Obesity and central adiposity in Japanese immigrants: role of the Western dietary pattern. $J$ Epidemiol, 12:431-8.

Foxcroft DR. 2005. Orlistat for the treatment of obesity: cost utility model. Obes Rev, 6:323-8.

Freeman DJ, Norrie J, Sattar N, et al. 2001. Pravastatin and the development of diabetes mellitus: evidence for a protective treatment effect in the West of Scotland Coronary Prevention Study. Circulation, 103:357-62.

Fung TT, Hu FB, Pereira MA, et al. 2002. Whole-grain intake and the risk of type 2 diabetes: a prospective study in men. Am J Clin Nutr, 76:535-40.

Fung TT, Schulze M, Manson JE, et al. 2004. Dietary patterns, meat intake, and the risk of type 2 diabetes in women. Arch Intern Med, $164: 2235-40$

Gruber A, Nasser K, Smith R, et al. 2006. Diabetes prevention: is there more than lifestyle changes? Int $J$ Clin Pract, 60:590-4.

Guerciolini R. 1997. Mode of action of orlistat. Int J Obes Relat Metab Disord, 21:S12-23.

Halpern A, Mancini MC, Suplicy H, et al. 2003. Latin-American trial of orlistat for weight loss and improvement in glycaemic profile in obese diabetic patients. Diabetes Obes Metab, 5:180-8.

Halpern A, Mancini MC. 2005. Diabesity: are weight loss medications effective? Treat Endocrinol, 4:65-74.

Hansson L, Lindholm LH, Niskanen L, et al. 1999. Effect of angiotensinconverting-enzyme inhibition compared with conventional therapy on cardiovascular morbidity and mortality in hypertension: the Captopril Prevention Project (CAPPP) randomised trial. Lancet, 353:611-6.

[HOPE] Heart Outcomes Prevention Evaluation Study Investigators. 2000. Effects of ramipril on cardiovascular and microvascular outcomes in people with diabetes mellitus: results of the HOPE study and MICROHOPE substudy. Lancet, 355:253-9.

Heymsfield SB, Segal KR, Hauptman J, et al. 2000. Effects of weight loss with orlistat on glucose tolerance and progression to type 2 diabetes in obese adults. Arch Intern Med, 160:1321-6.

Hoffmann J, Spengler M. 1994. Efficacy of 24-week monotherapy with acarbose, glibenclamide, or placebo in NIDDM patients. The Essen Study. Diabetes Care, 17:561-6.

Hoffmann J, Spengler M. 1997. Efficacy of 24-week monotherapy with acarbose, metformin, or placebo in dietary-treated NIDDM patients: the Essen-II Study. Am J Med, 103:483-90.
Hollander PA, Elbein SC, Hirsch IB, et al. 1998. Role of orlistat in the treatment of obese patients with type 2 diabetes. Diabetes Care, 21: 1288-1294.

Hsieh CJ, Wang PW, Liu RT, et al. 2005. Orlistat for obesity: benefits beyond weight loss. Diabetes Res Clin Pract, 67:78-83.

Hu FB, Sigal RJ, Rich-Edwards JW, et al. 1999. Walking compared with vigorous physical activity and risk of type 2 diabetes in women: a prospective study. JAMA, 282:1433-9.

Hu FB, Manson JE, Stampfer MJ, et al. 2001. Diet, lifestyle, and the risk of type 2 diabetes mellitus in women. $N$ Engl J Med, 345:790-7.

[IDF] International Diabetes Federation. 2006. Diabetes prevalence [online]. Accessed 12 October 2006. URL: http://www.idf.org/home/index. $\mathrm{cfm}$ ? node $=264$.

Isomaa B, Almgren P, Tuomi T, et al. 2001. Cardiovascular morbidity and mortality associated with the metabolic syndrome. Diabetes Care, 24:683-99.

James WPT, Rigby N, Leach R. 2004. The obesity epidemic, metabolic syndrome and future prevention strategies. Eur J Cardiovasc Prev Rehabil, 11:3-8.

James WPT. 2005. The SCOUT study: risk-benefit profile of sibutramine in overweight high-risk cardiovascular patients. Eur Heart J, 7(Suppl): L44-8.

Julius S, Kjeldsen SE, Weber M, et al. VALUE trial group. 2004. Outcomes in hypertensive patients at high cardiovascular risk treated with regimens based on valsartan or amlodipine: the VALUE randomised trial. Lancet, 363:2022-31.

Kanaya AM, Herrigton D, Vittinghoff E, et al. for the Heart and Estrogen/Progestin Replacement Study (HERS). 2003. Glycemic effects of postmenopausal hormone therapy: the Heart and Estrogen/Progestin Replacement Study: a randomized, double-blind, placebo-controlled trial. Ann Intern Med, 138:1-9.

Keating GM, Jarvis B. 2001. Orlistat: in the prevention and treatment of type 2 diabetes mellitus. Drugs, 61:2107-19; discussion 2120-1.

Kelley DE, Williams K, Price J, et al. 2001. Plasma fatty acids, adiposity and variance of skeletal muscle insulin resistance in type 2 diabetes mellitus. J Clin Endocrinol Metab, 86:5412-19.

Kelley DE, Bray GA, Pi-Sunyer FX, et al. 2002. Clinical efficacy of orlistat therapy in overweight and obese patients with insulin-treated type 2 diabetes: a 1-year randomized controlled trial. Diabetes Care, 25:1033-41. Erratum in: Diabetes Care, 26:971.

Kelley DE, Kuller LH, McKolanis TM, et al. 2004. Effects of moderate weight loss and orlistat on insulin resistance, regional adiposity, and fatty acids in type 2 diabetes. Diabetes Care, 27:33-40.

Kissebah AH, Krakower GR. 1994. Regional adiposity and morbidity. Physiol Rev, 74:761-811.

Knowler WC, Pettitt DJ, Saad MF, et al. 1990. Diabetes mellitus in the Pima Indians: incidence, risk factors and pathogenesis. Diab Metab Rev, 6:1-27.

Knowler WC, Barrett-Connor E, Fowler SE, et al. 2002. Reduction in the incidence of type 2 diabetes with lifestyle intervention or metformin. N Engl J Med, 346:393-403.

Kosaka K, Noda M, Kuzuya T. 2005. Prevention of type 2 diabetes by lifestyle intervention: a Japanese trial in IGT males. Diabetes Res Clin Pract, 67:152-62.

Kriska AM, Pereira MA, Hanson RL, et al. 2001. Association of physical activity and serum insulin concentrations in two populations at high risk for type 2 diabetes but differing by BMI. Diabetes Care, 24:1175-80.

Lacey LA, Wolf A, O'shea D, et al. 2005. Cost-effectiveness of orlistat for the treatment of overweight and obese patients in Ireland. Int $J$ Obes (Lond). 29:975-82.

Lindgren P, Lindstrom J, Tuomilehto J, et al. DPS Study Group. 2007. Lifestyle intervention to prevent diabetes in men and women with impaired glucose tolerance is cost-effective. Int $J$ Technol Assess Health Care, 23:177-83.

Lindholm LH, Persson M, Alaupovic P, et al. 2003. Metabolic outcome during 1 year in newly detected hypertensives: results of the Antihypertensive Treatment and Lipid Profile in a North of Sweden Efficacy Evaluation (ALPINE study). J Hypertens, 21:1563-74. 
Lopez-Ridaura R, Willet CW, Rimm BE, et al. 2004. Magnesium intake and risk of type 2 diabetes in men and women. Diabetes Care, 27:134-9.

Lovejoy JC. 1999. Dietary fatty acids and insulin resistance. Curr Atheroscler Rep, 1:215-20.

Maetzel A, Ruof J, Covington M, et al. 2003. Economic evaluation of orlistat in overweight and obese patients with type 2 diabetes mellitus. Pharmacoeconomics, 21:501-12.

Mancia G, Brown M, Castaigne A, et al. 2003. INSIGHT. Outcomes with nifedipine GITS or Co-amilozide in hypertensive diabetics and nondiabetics in Intervention as a Goal in Hypertension (INSIGHT). Hypertension, 41:431-6.

Marshall JA, Hamman RF, Baxter J. 1991. High-fat, low-carbohydrate diet and the etiology of non-insulin-dependent diabetes mellitus: The San Luis Valley Diabetes Study. Am J Epidemiol, 134:590-603.

Mather HM, Keen H. 1985. The Douthall Diabetes survey: prevalence of known diabetes in Asians and Europeans. Br Med J, 291:1081-4.

Meier JJ, Gallwitz B, Nauck MA. 2003. Glucagon-like peptide 1 and gastric inhibitory polypeptide: potential applications in type 2 diabetes mellitus. BioDrugs, 17:93-102.

Meyer KA, Kushi LH, Jacobs DR Jr, et al. 2000. Carbohydrates, dietary fiber, and incident type 2 diabetes in older women. Am J Clin Nutr, 71:921-30.

Miles JM, Leiter L, Hollander P, et al. 2002. Effect of orlistat in overweight and obese patients with type 2 diabetes treated with metformin. Diabetes Care, 25(7):1123-8. Erratum in: Diabetes Care, 25(9):1671.

Mokdad AH, Ford ES, Bowman BA, et al. 2000. Diabetes trends in the U.S.: 1990-1998. Diabetes Care, 23:1278-83.

Monteiro CA, Benicio MHA, Conde WL, et al. 2000. Shifting obesity trends in Brazil. Eur J Clin Nutr, 43:341-6.

Narayan KMW, Boyle JP, Thompson TJ, et al. 2003. Lifetime risk for diabetes mellitus in the United States. JAMA, 290:1884-90.

Nauck MA, Meier JJ. 2005. Glucagon-like peptide 1 and its derivatives in the treatment of diabetes. Regul Pept, 128:135-48.

Norris SL, Chowdhury FM, Van Le K, et al. 2006. Effectiveness of community health workers in the care of persons with diabetes. Diabet Med, 23:544-56.

Padwal R, Laupacis A. 2004. Antihypertensive therapy and incidence of type 2 diabetes: a systematic review. Diabetes Care, 27:247-55.

Padwal R, Majumdar SR, Johnson JA, et al. 2005. A systematic review of drug therapy to delay or prevent type 2 diabetes. Diabetes Care, 28:736-44.

Pan XR, Li GW, Hu YH, et al. 1997. Effects of diet and exercise in preventing NIDDM in people with impaired glucose tolerance: the Da Qing IGT and Diabetes Study. Diabetes Care, 20:537-44.

Park KS. 2004. Prevention of type 2 diabetes mellitus from the viewpoint of genetics. Diabetes Res Clin Pract, 66(Suppl 1):S33-5.

Park KS, Shin HD, Park BL, et al. 2006a. Putative association of peroxisome proliferator-activated receptor gamma co-activator 1beta (PPARGC1B) polymorphism with type 2 diabetes mellitus. Diabet Med, 23:635-42.

Park KS, Shin HD, Park BL, et al. 2006. Polymorphisms in the leptin receptor (LEPR) - putative association with obesity and T2DM. J Hum Genet, 51:85-91.

Pepine CJ, Handberg EM, Cooper-DeHoff RM, et al. INVEST Investigators. 2003. A calcium antagonist vs a non-calcium antagonist hypertension treatment strategy for patients with coronary artery disease. The International Verapamil-Trandolapril Study (INVEST): a randomized controlled trial. JAMA, 290:2805-16.

Perry IJ, Wannamethee SG, Walker MK, et al. 1995. Prospective study of risk factors for development of non-insulin dependent diabetes in middle aged British men. Br Med J, 310:560-4.

Piatti PM, Monti LD, Davis SN, et al. 1996. Effects of an acute decrease in non-esterified fatty acid levels on muscle glucose utilization and forearm indirect calorimetry in lean NIDDM subjects. Diabetologia, 1996:103-12.

Pontiroli AE, Folli F, Paganelli M, et al. 2005. Laparoscopic gastric banding prevents type 2 diabetes and arterial hypertension and induces their remission in morbid obesity: a 4-year case-controlled study. Diabetes Care, 28:2703-9.
Prisant LM. 2004. Preventing type II diabetes mellitus. J Clin Pharmacol, 44:406-13.

Randle PJ, Garland PB, Hales CN, et al. 1963. The glucose fatty-acid cycle. Its role in insulin sensitivity and the metabolic disturbances of diabetes mellitus. Lancet, 13:785-9.

Randle PJ. 1998. Regulatory interactions between lipids and carbohydrates: the glucose fatty acid cycle after 35 years. Diabetes Metab Rev, 14:263-83.

Reaven GM. 1988. The role of insulin resistance in human disease. Diabetes, 37:1595-1607.

Retnakaran R, Hanley AJ, Zinman B. 2006. Does hypoadiponectinemia explain the increased risk of diabetes and cardiovascular disease in South asians? Diabetes Care, 29:1950-4.

Richelsen B, Tonstad S, Rössner S, et al. 2007. Effect of orlistat on weight regain and cardiovascular risk factors following a very-low-energy diet in abdominally obese patients: a 3-year randomized, placebo-controlled study Diabetes Care, 30:27-32.

Rossner S, Sjöström L, Noack R, et al. 2000. Weight loss, weight maintenance, and improved cardiovascular risk factors after 2 years treatment with orlistat for obesity. European Orlistat Obesity Study Group. Obes Res, 8:49-61.

Samuelsson L, Gottsater A, Lindgarde F. 2003. Decreasing levels of tumour necrosis factor alpha and interleukin 6 during lowering of body mass index with orlistat or placebo in obese subjects with cardiovascular risk factors. Diabetes Obes Metab, 5:195-201.

Santomauro AT, Boden G, Silva ME, et al. 1999. Overnight lowering of free fatty acids with Acipimox improves insulin resistance and glucose tolerance in obese diabetic and nondiabetic subjects. Diabetes, 48:1836-41.

Satterfield DW, Volansky M, Caspersen CJ, et al. 2003. Community-based lifestyle interventions to prevent type 2 diabetes. Diabetes Care, 26:2643-52.

Saydah SH, Loria CM, Eberhardt MS, et al. 2001. Subclinical states of glucose intolerance and risk of death in the U.S. Diabetes Care, 25:447-53.

Scheen AJ, Ernest P. 2002. New antiobesity agents in type 2 diabetes: overview of clinical trials with sibutramine and orlistat. Diabetes Metab, 28:437-45.

Scheen AJ. 2003. Is there a role for alpha-glucosidase inhibitors in the prevention of type 2 diabetes mellitus? Drugs, 63:933-51.

Schulz LO, Bennett PH, Ravussin E, et al. 2006. Effects of traditional and western environments on prevalence of type 2 diabetes in Pima Indians in Mexico and the US. Diabetes Care, 29:1866-71.

Sjöström L, Rissanen A, Andersen T, et al. European Multicentre Orlistat Study Group. 1998. Randomised placebo-controlled trial of orlistat for weight loss and prevention of weight regain in obese patients. Lancet, 352:167-72.

Sjöström L, Lindroos AK, Peltonen M, et al. 2004. Lifestyle, diabetes, and cardiovascular risk factors 10 years after bariatric surgery. $N$ Engl $J$ Med, 351:2683-93.

Swinburn BA, Metcalf PA, Ley SJ. 2001. Long-term (5-year) effects of a reduced-fat diet intervention in individuals with glucose intolerance. Diabetes Care, 24:619-24.

Tan K, Tso A, Tam S, et al. 2002. Acute effect of orlistat on post-prandial lipaemia and free fatty acids in overweight patients with type 2 diabetes mellitus. Diabet Med, 19:944-8.

Tenenbaum A, Motro M, Fisman EZ, et al. 2004. Peroxisome proliferator-activated receptor ligand bezafibrate for prevention of type 2 diabetes mellitus in patients with coronary artery disease. Circulation, 109:2197-202.

Thomsen C, Storm H, Holst JJ, et al. 2003. Differential effects of saturated and monounsaturated fats on postprandial lipemia and glucagon-like peptide 1 responses in patients with type 2 diabetes. Am J Clin Nutr, 77:605-11.

Tong PC, Lee ZS, Sea MM, et al. 2002. The effect of orlistat-induced weight loss, without concomitant hypocaloric diet, on cardiovascular risk factors and insulin sensitivity in young obese Chinese subjects with or without type 2 diabetes. Arch Intern Med, 162:2428-35. 
Torgerson JS, Hauptman J, Boldrin MN, et al. 2004. XENical in the prevention of diabetes in obese subjects (XENDOS) study: a randomized study of orlistat as an adjunct to lifestyle changes for the prevention of type 2 diabetes in obese patients. Diabetes Care, 27:155-61. Erratum in: Diabetes Care, 2004 27:856.

Tsai AG, Wadden TA. 2005. Systematic review: an evaluation of major commercial weight loss programs in the United States. Ann Intern Med, 142:56-66.

Tuomilehto J, Lindstron J, Eriksson JG, et al. 2001. Prevention of type 2 diabetes mellitus by changes in lifestyle among subjects with impaired glucose tolerance. $N$ Engl J Med, 344:1343-50.

Tuomilehto J. 2005. Primary prevention of type 2 diabetes: lifestyle intervention works and saves money, but what should be done with smokers? Ann Intern Med, 142:381-3.

[UKPDS] United Kingdom Prospective Diabetes Study Group. 1995. UK prospective diabetes study 16: overview of 6 years' therapy of type II diabetes. Diabetes, 44:1249-58.

Uwin N, Shaw J, Zimmet P, et al. 2002. Impaired glucose tolerance and impaired fasting glycaemia: the current status on definition and intervention. Diab Med, 19:708-23.

Valsamakis G, McTernan PG, Chetty R, et al. 2004. Modest weight loss and reduction in waist circumference after medical treatment are associated with favorable changes in serum adipocytokines. Metabolism, $53: 430-4$.

Van Dam RM, Rimm EB, Willett WC, et al. 2002. Dietary patterns and risk of type 2 diabetes mellitus in US men. Ann Intern Med, 136:201-9.

Van Dam RM, Hu FB. 2005. Coffee consumption and risk of type 2 diabetes: a systematic review. JAMA, 294:97-104

Vilsboll T, Krarup T, Sonne J, et al. 2003. Incretin secretion in relation to meal size and body weight in healthy subjects and people with type 1 and type 2 diabetes mellitus. J Clin Endocrinol Metab, 88:2706-13

Wang Y, Mi J, Shan XY, et al. 2007. Is China facing an obesity epidemic and the consequences? The trends in obesity and chronic disease in China. Int J Obes (Lond), 31:177-88.

Weyer C, Bogardus C, Mott DM, et al. 1999. The natural hystory of insulin secretory dysfunction and insulin resistance in the pathogenesis of type 2 diabetes mellitus. J Clin Investig, 104:787-94.

Wild S, Roglic G, Green A, et al. 2004. Global prevalence of diabetes: estimates for the year 2000 and projections for 2030. Diabetes Care, 27:1047-53.
Williams KV, Mullen ML, Kelley DE, et al. 1998. The effect of short periods of caloric restriction on weight loss and glycemic control in type 2 diabetes. Diabetes Care, 21:2-8.

Wing RR, Koeske R, Epstein LH, et al. 1987. Long-term effects of modest weight loss in type II diabetic patients. Arch Intern Med, 147:1749-53.

Wing RR, Shoemaker M, Marcus MD, et al. 1990. Variables associated with weight loss and improvements in glycemic control in type II diabetic patients in behavioral weight control programs. Int J Obes, 14:495-503.

[WHO] World Health Organization. 2000. Obesity: preventing and managing the global epidemic. Report of WHO consultation on obesity. Geneva: World Health Organization.

Wu SI, Chou P, Tsai ST. 2001. The impact of years since menopause on the development of impaired glucose tolerance. J Clin Epidemiol, 54:117-20.

Xu G, Stoffers DA, Habener JF, et al. 1999. Exendin-4 stimulates both betacell replication and neogenesis, resulting in increased beta-cell mass and improved glucose tolerance in diabetic rats. Diabetes, 48:2270-6.

Yusuf S, Ostergren JB, Gerstein HC, et al. Candesartan in Heart FailureAssessment of Reduction in Mortality and Morbidity Program Investigators. 2005. Effects of candesartan on the development of a new diagnosis of diabetes mellitus in patients with heart failure. Circulation, 112:48-53. Erratum in: Circulation, 112:e292.

Zacharova J, Chiasson JL, Laakso M; STOP-NIDDM Study Group. 2005a. The common polymorphisms (single nucleotide polymorphism [SNP] +45 and $\mathrm{SNP}+276$ ) of the adiponectin gene predict the conversion from impaired glucose tolerance to type 2 diabetes: the STOP-NIDDM trial. Diabetes, 54:893-9.

Zacharova J, Todorova BR, Chiasson JL, et al. STOP-NIDDM Study Group. 2005b. The G-250A substitution in the promoter region of the hepatic lipase gene is associated with the conversion from impaired glucose tolerance to type 2 diabetes: the STOP-NIDDM trial. J Intern Med, 257:185-93.

Zhang Y, Howard BV, Cowan LD, et al. 2002. The effect of estrogen use on levels of glucose and insulin and the risk of type 2 diabetes in American Indian postmenopausal women: the Strong Heart study. Diabetes Care, 25:500-4.

Zhi J, Melia AT, Eggers H, et al. 1995. Review of limited systemic absorption of orlistat, a lipase inhibitor, in healthy human volunteers. J Clin Pharmacol, 35:1103-8. 